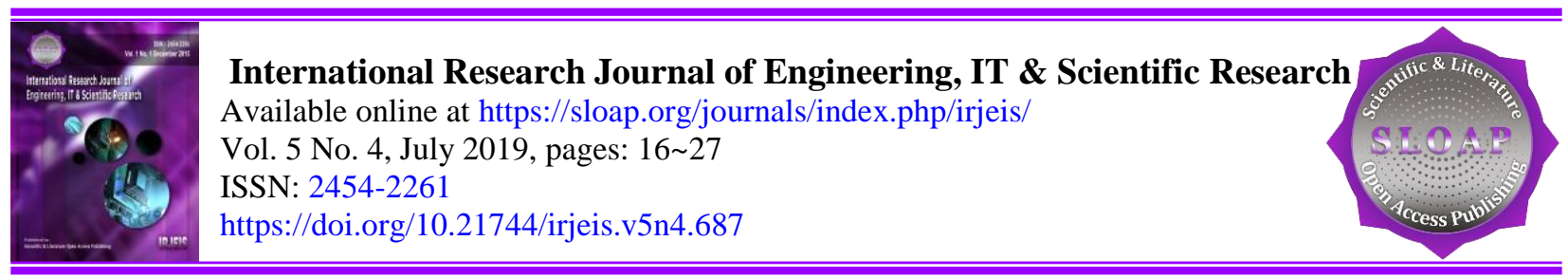

\title{
Comparative Estimation of Models with Different Structures for Estimation of Mechanical Properties of Light Steel Profiles
}

Article history:

Received: 18 March 2019

Accepted: 31 May 2019

Published: 31 July 2019

\section{Keywords:}

properties estimation;

steel profiles;

mathematical modeling;

steel production;

engineering systems;

\begin{abstract}
The paper presents linear, quadratic, signomial and radial-based neural networks for the estimation of the mechanical properties of steel profiles for construction obtained from the chemical composition of the batches, the cross-section of the profile to be laminated, for the lamination workshops taken as case studies. As primary information, a database with the batches produced in the Antillana de Acero rolling mills is used for more than ten years. The results obtained show that the radial base neural networks applying Landweber's iterative regularization method to network training provide the highest precision. The signomial, quadratic and linear models reach similar values of precision taking as a criterion of comparison the standard deviation of the estimate with respect to the results of the passive experiments obtained from the quality control of the production. The modeling work is done for the case studies of the laminating workshops 250 and 300 of the steel company Antillana de Acero.
\end{abstract}

2454-2261 ${ }^{\odot}$ Copyright 2019. The Author. This is an open-access article under the CC BY-SA license (https://creativecommons.org/licenses/by-sa/4.0/) All rights reserved.

\section{Author correspondence:}

Zambrano Ortíz Denis Joaquín,

Technical University of Manabí, Department of Industrial Engineering, Ecuador.

Email address: dzambrano@utm.edu.ec / deniszambrano73@ hotmail.com

\section{Introduction}

The estimation of properties of materials is an essential requirement for the allocation of their destination of use. Among these materials, steel stands out for the versatility of its properties, being currently a strategic line for the growth of countries. Within the steel productions, the industry of the laminated profiles for the construction constitutes a line of high economic repercussion in the country.

a Technical University of Manabí, Department of Industrial Engineering, Ecuador

b Technical University of Manabí, Department of Industrial Engineering, Ecuador

${ }^{c}$ Study Center of Mathematics for Technical Sciences, Technological University of Havana 
This production refers to corrugated bars, round and square profiles for national consumption and export to countries in the area and is concentrated in the mills of the Antillana de Acero and Acinox Tunas Companies, which also have respective electric steelworks in charge to provide the semi-product in the form of billets.

The need to allocate destiny to the billets produced in the steel mills arises in such away. In other words, it is necessary to define the workshop profile and quality grade that should be assigned to each batch produced, in order to optimize the efficiency criteria of the production company, ensuring the quality indicators required by customers.

The problem of generating destination options is directly related to the general problem of optimal selection of materials, which has been studied by numerous authors. In effect, the problem of which batches have to be used in certain destinations of the set of batches in the process is a problem of optimal selection of materials (Ashby et al., 2010; Bin, 1994).

In the works Ashby (2011); Ashby et al., (2010), the development of material selection methodologies is exposed. The methodology exposed in these works has great acceptance in the engineering of modern materials, those that start from the contrast that arises between the combination of the attributes of the processes and the properties of the materials by means of special graphics (Ashby, 2011; Ashby et al., 2010). This methodology, being of a general nature, avoids indicators and restrictions associated with technical and organizational factors, determining the generation of destination options for batches of the steel industry, discriminant to reduce the number of alternatives to be evaluated in problems of material selection (Guerra, 1994). The destination of batches is a component part of the general direction, of the production process of steel companies, so it study must be done from the tasks associated with the direction of steel production and is an essential task for saving materials premiums, as a consequence of the better use of the batches in process and allows to guarantee a correct distribution of resources in the steel companies (Arzola, 1998; Arzola, 2000; Arzola \& Suárez, 1993; Arzola, 2009).

The mathematical models that appear in the available literature for the estimation of the properties are statistical, linear and quadratic (Arzola \& Suárez, 1993; Arzola, 2009; Elanayar \& Shin, 1994). Like multilayer perceptrons, they serve as universal function approximations Elanayar (1999); Karayiannis, 1999; Demuth \& Beale, 2002; Neto et al., 2013), these networks provide nonlinear models with greater precision than statistical models (Elanayar \& Shin, 1994; Martin Del Brío \& Sanz, 2001; Wesley, 1997). This special type of networks has great power of generalization when the data define smooth functions, however, when they come from measurements noisy, it is possible that its generalization decays considerably (Wesley, 1997).

The process of training and learning a radial base network can be faced from the point of view of the inverse problems, which allow knowing the mathematical model or the causes that they originate a certain known effect, Demuth \& Beale, (2002); Morozov (1993); Silva (2012); Silva (2005), this solution approach allows applying regularization strategies to this problem, with which the original problem becomes an approximation, less affected by the noise of the experimental data (Morozov, 1993; Moura et al., 2013; Snieder \& Trampert, 1999).

\section{Materials and Methods}

At the same time, in the universal literature, there are no satisfactory results that allow to accurately evaluate the mechanical properties of steels for the production of corrugated bars profiles for construction, so the development of such procedures becomes relevant (Sánchez et al., 2018; Hernández et al., 2017).

The influencing factors on the mechanical properties are constituted by the chemical composition of the steel, thermal regime and deformation of the steel. The latter is practically constant in each workshop, depending on the profile produced, that is, its cross-section, represented by the diameter $(D)$ or its square $\left(D^{2}\right)$. For the low alloy profiles for the construction produced in the companies of the country, determinants of the chemical composition are the carbon $(C)$, silicon $(\mathrm{Si})$ and manganese $(\mathrm{Mn})$. Thus, the percentage composition of these three chemical elements is adopted as variables for the evaluation of properties. The properties to be evaluated are the yield strength $(R e)$ and the breakage limit $(R m)$ of the batches.

Conditions of experimentation and analysis of the results. In the laboratory of mechanical tests of the company Caso de Estudio, a database of 7896 measurements of the yield strength and breakage of batches with different values of chemical composition and diameter and 6743 measurements of workshop 300 was taken. The data were not treated previously (Parraga et al., 2017; Simpen et al., 2018).

Joaquín, Z. O. D., Mariuxi, L. V. R., \& José, A. R. (2019). Comparative estimation of models with different structures for estimation of mechanical properties of light steel profiles. International Research Journal of Engineering, IT \& Scientific Research, 5(4), 16-27. https://doi.org/10.21744/irjeis.v5n4.687 


\section{Results and Discussions}

\section{Linear}

Models Linear models for estimating properties are the most widespread in practice. The results obtained by modeling the estimation of properties are presented below.

Workshop 250.

The result of the modeling, aided by the Statgraphics linear regression package, considering the diameter of the final profile as representative of the cross-section of the finished product.

$R e=29.71+38.3 C+6.53 \mathrm{Mn}+5.4$ Yes $-0.35 \mathrm{D}$

The R-squared statistic indicates that the model explains $81 \%$ of the variability of $R e$.

The standard error of the estimate is $1.84 \mathrm{Kgf} / \mathrm{mm}^{2}$. This value can be used to construct the residuals of the new possible observations around the calculated values.

Rm, workshop 250

The modeling result is as follows:

$R m=33.60+73.78 C-0.32 \mathrm{D}+13.25 \mathrm{Mn}+9.4$ Yes

The R-squared statistic indicates that the model explains $84.83 \%$ of the variability $R m$.

The standard error of the estimate is $2.48 \mathrm{Kgf} / \mathrm{mm}^{2}$. This value can be used to construct the residuals of the new possible observations around the calculated values.

Workshop 300, Re

The result of the modeling, considering the diameter of the final profile as representative of the cross-section of the finished product provides the following model.

$R e=27.95+40.3 C-0.28 D+7.10 M n+5.08 Y e s$

A significant relationship between the variables is reached at the $99 \%$ confidence level.

The R-squared statistic indicates that the model explains $85.4 \%$ of the variability of $R e$.

The standard error of the estimate is $1.75 \mathrm{Kgf} / \mathrm{mm}^{2}$. This value can be used to construct the residuals of the new possible observations around the calculated values.

Workshop 300, Rm

The modeling result is as follows:

$R m=30.11+84.13 C-0.22 D+13.13 M n+6.29$ Yes

The R-squared statistic indicates that the model explains $89.53 \%$ of the variability of $R m$.

The standard error of the estimate is $2.53 \mathrm{Kgf} / \mathrm{mm}^{2}$. This value can be used to construct the residuals of the new possible observations around the calculated values.

In all cases, the Durbin-Watson (DW) statistician's test determines that there is no significant correlation based on the order in which the data is found in the database and

the P-value in the ANOVA table is less than 0.01, which indicates that the highest order term is statistically significant at the $99 \%$ confidence level.

\section{Quadratic models}

Workshop 250, Re

The result of modeling, considering not only the squares of the variables but their interaction, provides the following model.

$R e=25,329+26,8247 C+16.64 C^{2}-0.016 D^{2}+16.22 M n-6.2 M n^{2}+13.6 Y e s-21.95 Y_{e s}^{2}$

The R-squared statistic indicates that the model explains $81.6 \%$ of the variability of $R e$. 
The standard error of the estimate is $1.83 \mathrm{Kgf} / \mathrm{mm}^{2}$. This value can be used to construct the residuals of the new possible observations around the calculated values.

Workshop 250, Re

The result of modeling, considering not only the squares of the variables but their interaction, provides the following model

$R m=36.6664+39.27 C+19.69 M n+23.48 Y e s-0.74 D+37.25 C^{2}-7.30 M n^{2}-32.78 Y e s^{2}+0.02 D^{2}+16.51 C M n$

The R-squared statistic indicates that the model explains $85.11 \%$ of the variability of $R m$.

The standard error of the estimate is $2.78 \mathrm{Kgf} / \mathrm{mm}^{2}$. This value can be used to construct the residuals of the new possible observations around the calculated values.

Workshop 300, Re

The output shows the results of quadratic adjustment between $R e$ and the independent variables. The equation of the adjusted model is

$\operatorname{Re}=25.75+42.36 C-19.55 C^{2}+13.04 C M n-0.17 D-0.003 D^{2}+6.80 M n-2.15 M n^{2}+14.31 Y^{2} s-21.51 Y e s^{2}$

The R-squared statistic indicates that the model explains $85.6 \%$ of the variability of $R e$.

The standard error of the estimate is $1.74 \mathrm{Kgf} / \mathrm{mm}^{2}$. This value can be used to construct the residuals of the new possible observations around the calculated values.

The equation of the fitted model of $\mathrm{Rm}$ is:

$R m=24.20+0.24 D+72.65 C+14.49 M n+34.87$ Yes $-0.01 D^{2}-2.67 M n^{2}-63.78 Y_{e s}^{2}+11.72 C M n$

The R-squared statistic indicates that the model explains $89.69 \%$ of the variability of $R m$.

The standard error of the estimate is $2.51 \mathrm{Kgf} / \mathrm{mm}^{2}$. This value can be used to construct the residuals of the new possible observations around the calculated values.

In all cases, the Durbin-Watson (DW) statistician's test determines that there is no significant correlation based on the order in which the data is found in the database and

the P-value of the ANOVA table is smaller 0.01, so a significant relationship of the variables is reached at the $99 \%$ confidence level.

\section{Signomial models}

The function, $y=c x_{1}^{\alpha_{1}} x_{2}^{\alpha_{2}} \ldots x_{n}^{\alpha_{n}}=c \prod_{i=1}^{n} x_{i}^{\alpha_{i}}$

It is called a monomial function of the positive variables $x_{1}, x_{2}, \ldots, x_{n}$. The constant $c>0$ is called the coefficient of the monomial function, and the real constants $\alpha_{1}, \alpha_{2}, \ldots, \alpha_{n}$ exponents of the monomial function $\square 4 \square, \square 21 \square$. It is called polynomial function with $m$ terms to the sum of one or more monomials, that is, a function of the form

$$
g(x)=\sum_{k=1}^{m} c_{k} x_{1}^{\alpha_{1 k}} x_{2}^{\alpha_{2 k}} \ldots x_{n}^{\alpha_{n k}}=\sum_{k=1}^{m} c_{k} \prod_{i=1}^{n} x_{i}^{\alpha_{i k}}
$$

Where:

$c_{k}>0, \alpha_{i k} \in R, i=1,2, \ldots, n ; k=1,2, \ldots, m$. They are parameters and $x_{i}$ are positive variables. If $c_{k} \in R$, then $g(x)$ is called the signomial function. Thus, the signomial functions generalize the postinomial, quadratic, linear, etc., so that the precision of the adjustment by a signomial model can not, conceptually, be worse than the adjustment by any of the previous models, provided that this adjustment is made correctly.

The processing of the data is done according to the procedure explained in the paper $\square 21 \square$. Adjustment of $R e$, workshop 250:

Joaquín, Z. O. D., Mariuxi, L. V. R., \& José, A. R. (2019). Comparative estimation of models with different structures for estimation of mechanical properties of light steel profiles. International Research Journal of Engineering, IT \& 


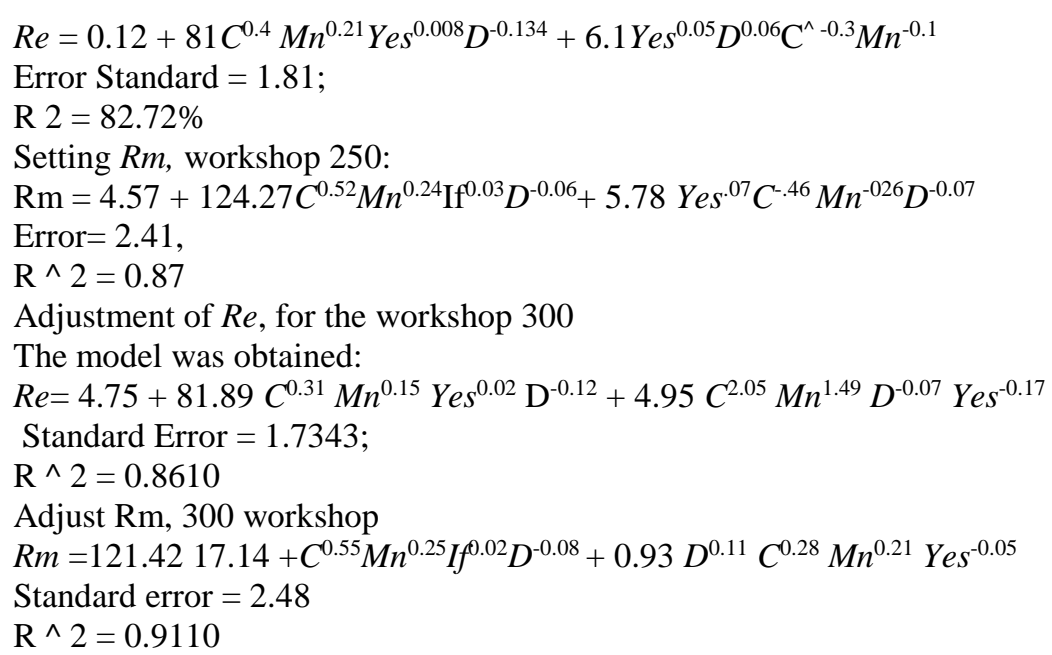

\section{Radial-based neural network models}

The architecture of an artificial radial-based neural network has three layers of neurons: one input, one hidden and one output. Input neurons only send information from the outside to the next layer. The neurons of the hidden layer employ an activation function of radial symmetry (usually Gaussian), which operates in dependence on the distance that separates the vector of inputs with respect to the vector of synaptic weights stored by each neuron (center of the function of radial base), evaluating the radial function in said difference. The neurons of the output layer are linear and essentially calculate the weighted sum of the outputs provided by the hidden layer (Martin Del Brío \& Sanz, 2001; Patan, 2008; Wesley, 1997; and Demuth \& Beale, 2002).

The output for this type of network is as follows:

$$
\left.R_{s}=\sum_{q=1}^{d} W_{s q} \cdot \phi r_{q}\right)+\lambda_{s}=\sum_{q=1}^{d} W_{s q} \cdot e^{\left(r_{q}^{2} \sigma_{q}^{2}\right.}+\lambda_{s}
$$

Where:

$\sigma_{q} \rightarrow$ Gaussian width node $q$

$r_{q} \rightarrow$ distance between the input vector from the center of the Gaussian node $q$

$W_{\mathrm{sq} \rightarrow}$ facilitates connection weight between the hidden neuron $q$ and output $s$

$\lambda_{s} \rightarrow$ threshold of the output node $s$

\subsection{Learning of Radial Based Neural Networks}

The first phase of the training or unsupervised phase consists of setting the size of the hidden layer, that is, the number of radial neurons. Then, in the supervised phase, two parameters of the hidden layer are determined that are essential for a good performance of the neural network in general: the center $\mathrm{c}$ and the width $\sigma$, which will take their definitive value once the learning is done. The value of the centers can be obtained using some supervised algorithm for clustering, such as the well-known k-means algorithm, where $\mathrm{k}$ refers to the number of radial nodes that one wishes to find (Martin Del Brío \& Sanz, 2001; Wesley, 1997). To obtain the values of the widths, we can calculate the uniform average of the distances from each center to the $b$ nearest centers.

The learning of the artificial neural networks of the radial base is generally of the hybrid type, being carried out in two stages. First, unsupervised training is carried out in the hidden layer, that is, the response of the radial basis functions to the input data is determined. Subsequently, supervised training is carried out in the output layer: With the response of the neurons of the hidden layer, the weights and pathways of the output layer are determined, so that the output is the desired in the training data (Patan, 2008).

$\mathrm{Be} ; K: \mathrm{R}^{m} \longrightarrow \mathrm{R}^{n}$ a linear operator, the process of searching the weights and pathways of the output layer can be formulated as follows: Find $w \in M_{n, m}(\mathrm{R})$ as the solution of the linear equation. 


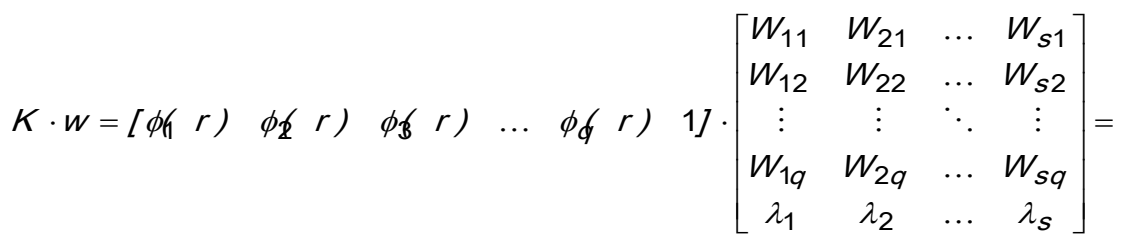

$=\left[\begin{array}{llll}R_{1} & R_{2} & \ldots & R_{S}\end{array}\right]=R$

(4)

This equation can be solved by the least-squares method. In this way, the radial-based neural networks leave an error of almost zero in the training data (Elanayar \& Shin, 1994; Martin Del Brío \& Sanz, 2001; and Patan, 2008), but many times a large error in the validation or generalization.

The search for the weights and pathways of the output layer, that is, the supervised phase of the training of the radialbased neural network, can be interpreted as the solution of a reverse problem.

\subsection{Literative Method of Landweber}

The Landweber method is a strategy for regularizing inverse problems (Silva \& Becceneri, 2009); Arzola \& Valdés, 2008). It is used to give an approximate solution of equation (4) when the measurements of the member on the right are contaminated with noise. The approximate solution of (4), $w^{\square}$ is computed by the iterative process

$$
w^{t, \delta}=\left(I-a K^{\prime} K\right) w^{t-1, \delta}+a K^{\prime} R^{\delta} ; w^{0, \delta}=0, t=1,2, \ldots
$$

$K^{\prime} \rightarrow$ denotes the conjugate operator Koperator.Now, be $K: X$ And a linear, compact and injective operator with dense image subspace; be $u \in \mathrm{R}, u>1$ y $R^{\delta} \in Y$ so that $\left\|R-R^{\delta}\right\| \leq \delta$ y $\left\|R-R^{\delta}\right\| \geq u \delta$; the following statements are valid

$\lim _{t \rightarrow \infty}\left\|K w^{t, \delta}-y^{\delta}\right\|=0, \forall \delta>0$; That is, the iterative process (6) can be performed until finding the integer $t=$ $t()$ the smallest with which it is guaranteed that $\| K w^{t,}-$ and $\| \leq u$. This constitutes the stop rule of algorithm.

$\left\|w^{t, \delta}-w\right\| \leq \sqrt{E \delta}$, Yes $w=K^{\prime} f \in R\left(K^{\prime}\right)$, if for some $e \square 0$ and for some $f$ with $\|f\| \leq E$, this is an approximation of the error made in computing the solution by the process (5).

In the first training stage of each neuronal network, 100 neurons were taken from the hidden layer and then the centers and widths were calculated. The centers were determined by the algorithm of the k-means, and the widths as the uniform mean of the distances from the center of each neuron to the 10 closest centers. Once this procedure was done, the number of neurons in the hidden layer was increased, adding 10 neurons in each experiment, until the best fit of the data was obtained in each case. The parameters found were 2250 radial-based neurons with a coefficient of determination $\mathrm{R}^{2}=88.57 \%$ using the validation data for workshop 250 . This means that the model obtained by the neural network explains $88.57 \%$ of the variations in the data, with a quadratic error of $0.0788 \mathrm{kgf} / \mathrm{mm} 2$. For Workshop 300, the best fit neural network is composed of 3002 neurons in the hidden layer, obtaining a coefficient of determination of R2 $=85.21 \%$ with a quadratic error of $0.0963 \mathrm{kgf} / \mathrm{mm} 2$. An increase in radial base neurons does not improve the fit in either case.

After the first phase of network training, the supervised phase of the output layer of each radial base network was carried out, using Landweber's iterative method as a regularization strategy. Once the hypotheses imposed by the algorithm were verified, the parameters of the output layer were determined. Figure 1 shows the errors of the adjustment of the yield limit by the radial-based neural network, where the Landweber method was used, in workshop 250. As observed, the errors in the generalization stage are not high, and they are within an acceptable range for the estimation of said mechanical property of the batches.

The errors in the adjustment of the limit of rupture are presented in figure 2. In the estimation of this property, there were greater errors than in the estimation of the yield limit, but they are considered acceptable because they are not so coarse.

Joaquín, Z. O. D., Mariuxi, L. V. R., \& José, A. R. (2019). Comparative estimation of models with different structures for estimation of mechanical properties of light steel profiles. International Research Journal of Engineering, IT \& Scientific Research, 5(4), 16-27. https://doi.org/10.21744/irjeis.v5n4.687 


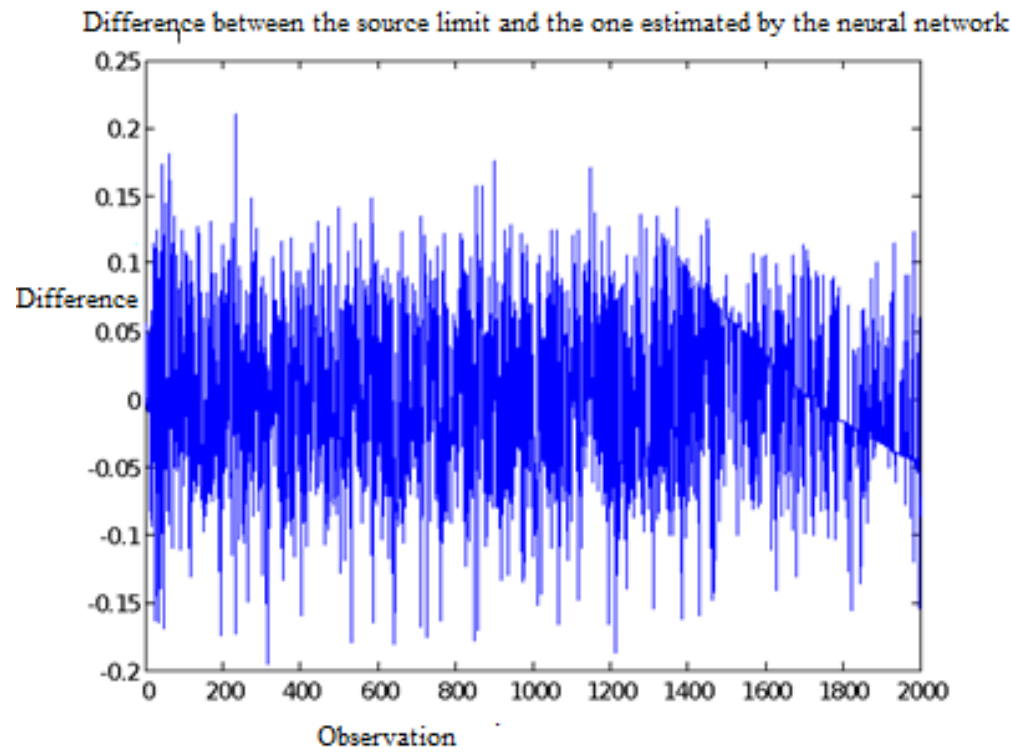

Figure 1. Errors in the generalization phase of the radial base network in the estimation of the yield strength (Workshop 250)

The coefficient of determination for the adjustment of the yield strength was $\mathrm{R}^{2}=95.43 \%$ and for the limit of rupture of $\mathrm{R}^{2}=93.51 \%$, with a quadratic error of 0.197 and 0.0265 , respectively. Both coefficients show a high explanation of the data by the model and a strong linear correlation between the experimental data and those estimated by the model.

In the estimation of the yield strength in workshop 300, results similar to those of workshop 250 were obtained. Figure 3 shows an allowable error in the estimation of the yield strength, whose coefficient of determination is $\mathrm{R}^{2}=$ $93.03 \%$. with a quadratic error of $0.369 \mathrm{kgf} / \mathrm{mm} 2$.

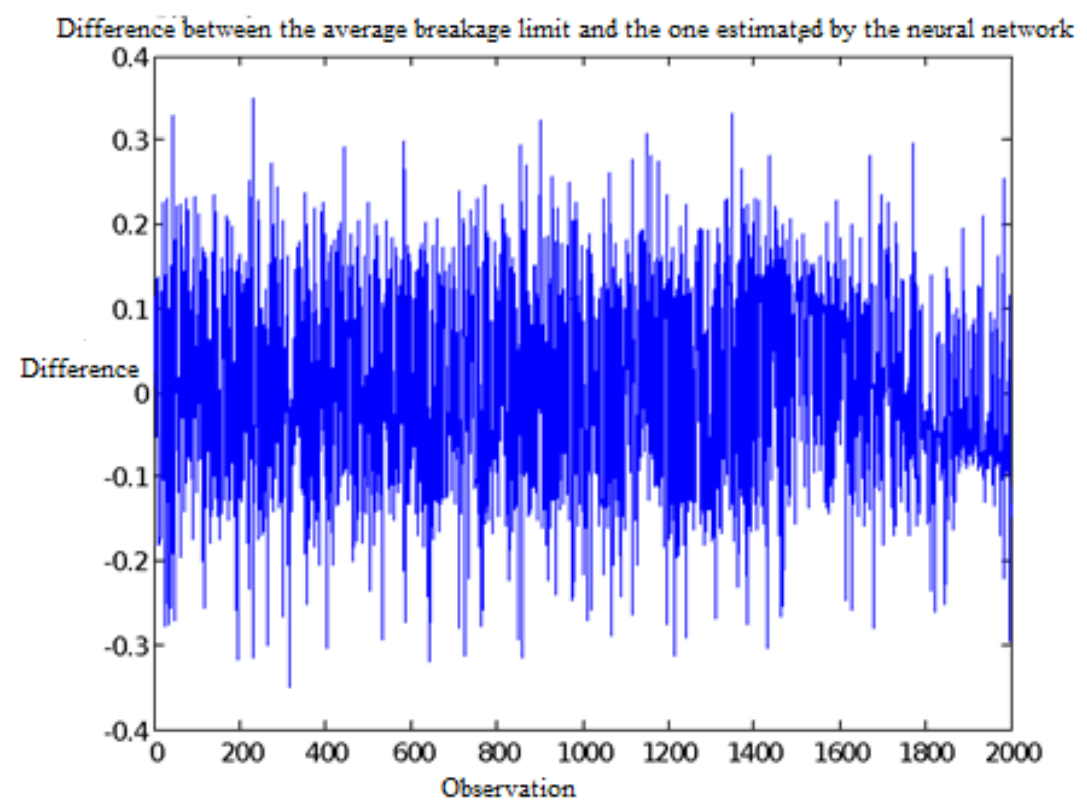

Figure 2. Errors in the generalization phase of the radial base network in the estimation of the breaking limit (Workshop 250). 
Adjustment errors in the breakage limit in shop 300 are greater than those in the creep limit estimate, but also acceptable. The coefficient of determination, in this case, is $\mathrm{R}^{2}=92.46 \%$, with a quadratic error of $0.301 \mathrm{kgf} / \mathrm{mm} 2$. Figure 4 shows the behavior of this property measured and estimated.

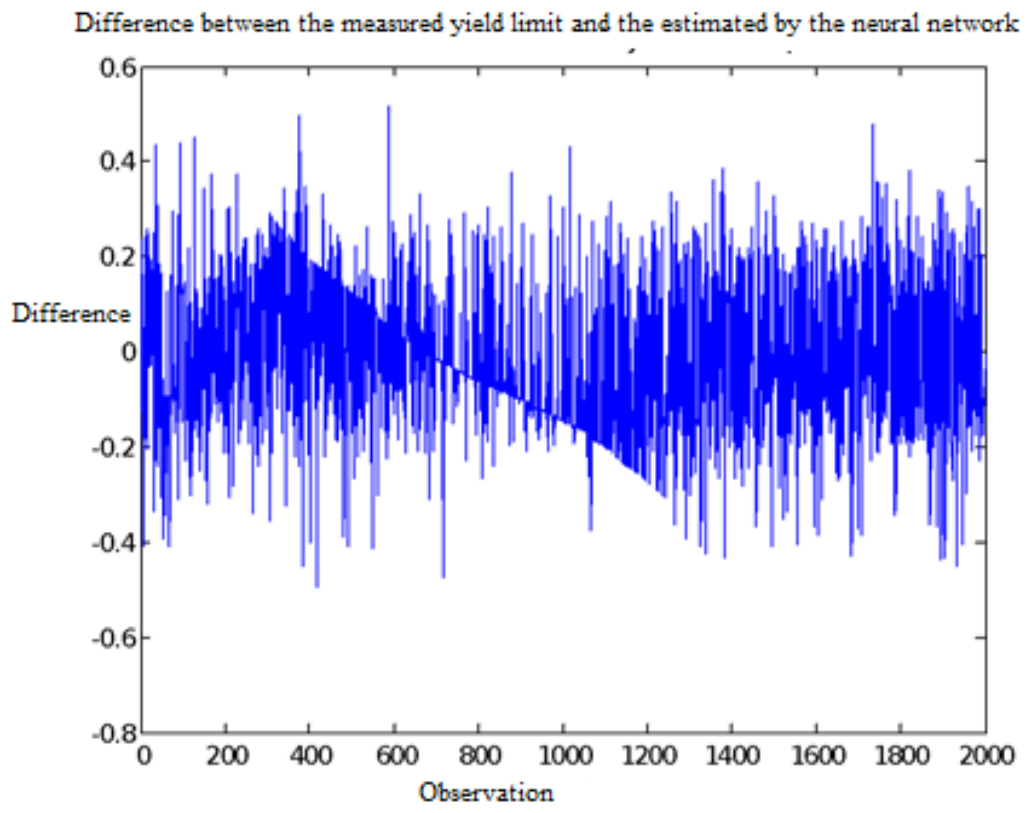

Figure 3. Errors in the generalization phase of the radial base network in the estimation of the yield strength

(Workshop300)

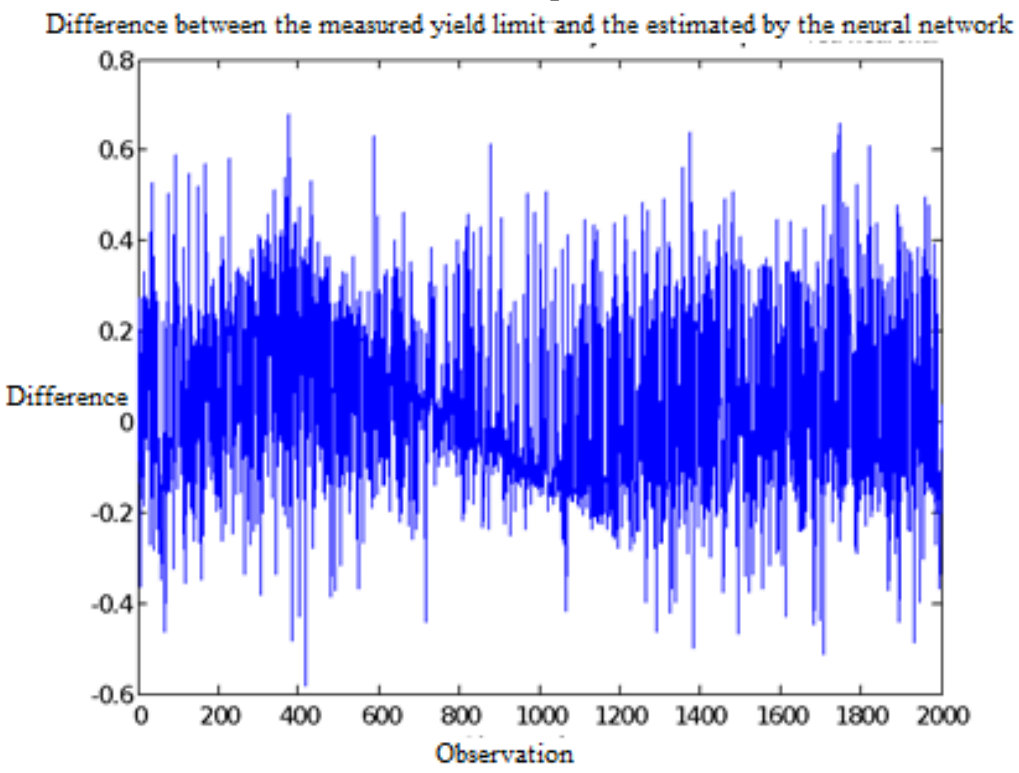

Figure 4. Errors in the generalization phase of the radial basis network in the estimation of the breakage limit (Workshop 300)

\subsection{Comparison of the Evaluation by Different Models}

The comparison is made based on the coefficient of determination and the standard error obtained during modeling by different models. Tables 1, 2, 3 and 4 show the results of this comparison.

Joaquín, Z. O. D., Mariuxi, L. V. R., \& José, A. R. (2019). Comparative estimation of models with different structures for estimation of mechanical properties of light steel profiles. International Research Journal of Engineering, IT \& Scientific Research, 5(4), 16-27. https://doi.org/10.21744/irjeis.v5n4.687 
Table 1

Comparison of the evaluation of mechanical properties by different models, workshop 250, $\operatorname{Re}$

\begin{tabular}{lll}
\hline $\begin{array}{l}\text { Indicator } \\
\text { Model }\end{array}$ & $\begin{array}{l}\text { Standard error } \\
\left(\mathrm{Kgf} / \mathrm{mm}^{2}\right)\end{array}$ & $\begin{array}{l}\text { Coefficient of } \\
\text { determination } \\
(\%)\end{array}$ \\
\hline Linear & 1,84 & 81 \\
Quadratic & 1.83 & 81.6 \\
Signomial & 1.81 & 82.72 \\
Neural networks & 0.197 & 95.43 \\
\hline
\end{tabular}

Table 2

Comparison of the evaluation of mechanical properties by different models, workshop 250, $\mathrm{Rm}$

\begin{tabular}{lll}
\hline $\begin{array}{l}\text { Indicator } \\
\text { Model }\end{array}$ & $\begin{array}{l}\text { Standard error } \\
\left(\mathrm{Kgf} / \mathrm{mm}^{2}\right)\end{array}$ & $\begin{array}{l}\text { Coefficient of } \\
\text { determination } \\
(\%)\end{array}$ \\
\hline Linear & 2.78 & 84.3 \\
Quadratic & 2.48 & 85.11 \\
Signomial & 2.41 & 0.87 \\
Neural networks & 0.1265 & 93.51 \\
\hline
\end{tabular}

Table 3

Comparison of evaluation of mechanical properties of different models, shop 300, Re

\begin{tabular}{lll}
\hline $\begin{array}{l}\text { Indicator } \\
\text { Model }\end{array}$ & $\begin{array}{l}\text { Errorstandard } \\
(\mathrm{Kgf} / \mathrm{mm})\end{array}$ & $\begin{array}{l}\text { Coefficient } \\
\text { Determination } \\
(\%)\end{array}$ \\
\hline Linear & 1.75 & 85.4 \\
Quadratic & 1.74 & 85.6 \\
Signomial & 1.73 & 86.1 \\
Neural networks & 0.37 & 93.03 \\
\hline
\end{tabular}

Table 4

Comparison of the evaluation of mechanical properties by different models, workshop 300, $\mathrm{Rm}$

\begin{tabular}{lll}
\hline $\begin{array}{l}\text { Indicator } \\
\text { Model }\end{array}$ & $\begin{array}{l}\text { Standard error } \\
\left(\mathrm{Kgf} / \mathrm{mm}^{2}\right)\end{array}$ & $\begin{array}{l}\text { Coefficient of } \\
\text { determination } \\
(\%)\end{array}$ \\
\hline Linear & 2.53 & 89.53 \\
Quadratic & 2.51 & 89,69 \\
Signomial & 2.48 & 91.1 \\
Neural networks & 0.301 & 92.46 \\
\hline
\end{tabular}

As can be seen, the quadratic and signomial models improve very little, in all cases, the quality indicators of respect to the linear model. However, a significant improvement is achieved by using radial-based neural networks.

\section{Conclusion}

The problem of generating metal destination options in steel companies is solved by minimizing the excess of mechanical properties, ensuring the required values of these for the fulfillment of the service designation. In the solution of this task, it is necessary to estimate said mechanical properties, which can be done with the help of different models. The quadratic and signomial models improve very little, in all the cases studied, the quality 
indicators of respect to the linear model. However, a significant improvement is achieved by using radial-based neural networks.

The model of radial-based neural networks does not achieve a good generalization for the studied case associated with the estimation of mechanical properties of the finished products of the production of light steel profiles from semi-products, steel billets, as the data come from noisy sources. However, when applying the Landweber method to the supervised training phase of the radial-based network, in the problem of estimating the yield strength and breakage of the batches, in both lamination workshops studied by the Antillean Steel Company, very favorable results were obtained. With this method of regularization applied in the training of the radial base network, seen as a reverse problem, the error in the adjustment was reduced by 11 times, so it can be concluded that the model, among the studied ones, that allows achieving the best evaluation is the radial-based neural network. This result allows to considerably improve the quality of the generated destination options.

Conflict of interest statement and funding sources

The authors declared that they have no competing interest.

Statement of authorship

The authors have a responsibility for the conception and design of the study. The authors have approved the final article.

\section{Acknowledgments}

The authors would like to thank the Editor of IRJEIS for their valuable time, support, and advice in completing the current study.

Joaquín, Z. O. D., Mariuxi, L. V. R., \& José, A. R. (2019). Comparative estimation of models with different structures for estimation of mechanical properties of light steel profiles. International Research Journal of Engineering, IT \& 


\section{References}

Arzola, J., (1989). Selection of Proposals. Editorial Technical Scientific, Havana.

Arzola, J., (2000). Engineering Systems First edition. Editorial Félix Varela, Havana.

Arzola, J., (2009). Monograph Analysis and Synthesis of Engineering Systems. Havana.

Arzola, J., Suárez, L., (1993). Rules of Conduct in the projection and conduction of steel heating processes. Rev. Argus, Saltillo.

Arzola, N., Menéndez, A., De León, M., García, E., \& Cabrera, A. (1998). Bases for the use of Fertilizers and Amendments. In: Basic Elements on Soils and Fertilizer Uses in the cultivation of CaBa de Az6car. Editors: M. PCrez and J. Campos. Department of Soils and Agrochemistry. INICA , 37-132.

Arzola, RJ and Valdés, OM (2008): Elaboration of Monomial, Posinomial and Signomial Approximation Functions. In XIV Scientific Convention of Engineering and Architecture, La Habana

Ashby, M. F., \& Cebon, D. (1993). Materials selection in mechanical design. Le Journal de Physique IV, 3(C7), C71 .

Ashby, M. F., Shercliff, H., \& Cebon, D. (2010). Materials Engineering, science, processing and design, Second Editions, Editorials Elsevier Ltd.

Bin, W. (1994). CAD "Interaction with CAPP". Manufacturing Systems Design and Analysis.

del Brío González, JA, \& Cimadevilla, BJ (2001). Environment and business: from confrontation to opportunity . Madrid: Civitas.

Demuth, H., \& Beale, M. (2002). Neural network toolbox for use with Matlab: User's Guide, Natick, USA: MathWorks.

Elanayar, S., \& Shin, Y. C. (1991). Tool wear estimation in turning operations based on radial basis functions. In Intelligent Engineering Systems Through Artificial Neural Networks (pp. 685-692). ASME Press.

Guerra, V.A. (1994). Behavior of the properties of the bars in the Antillana de Acero 200 laminator. Grade Thesis of the UDM. CUJAE, Havana

Hernández, E. H. O., Moncayo, E. H. O., Sánchez, L. K. M., \& Calderero, R. P. de. (2017). Behavior of clayey soil existing in the portoviejo canton and its neutralization characteristics. International Research Journal of Engineering, IT \& Scientific Research, 3(6), 1-10.

Karayiannis, N. B. (1999). Reformulated radial basis neural networks trained by gradient descent. IEEE transactions on neural networks, 10(3), 657-671. https://doi.org/10.1109/72.761725

Martín del Brío, B., \& Sanz Molina, A. (2001). Redes Neuronales y Sistemas Borrosos, 2da. Edición, Ra-Ma, Madrid, España.

Morozov, V. A., \& Stessin, M. (1993). Regularization methods for ill-posed problems (p. 257). Boca Raton, FL:: CRC press.

Neto, F. D. M., \& da Silva Neto, A. J. (2012). An introduction to inverse problems with applications. Springer Science \& Business Media.

Neto, W. P. F., Silvério, H. A., Dantas, N. O., \& Pasquini, D. (2013). Extraction and characterization of cellulose nanocrystals from agro-industrial residue-Soy hulls. Industrial Crops and Products, 42, 480-488.

Parraga, WER, Parraga, MAC, Salazar, MJV, \& Albear, JJH (2017). Reusing the coconut clay (brick) as construction material. International Research Journal of Engineering, IT \& Scientific Research, 3 (4), $102-109$.

Patan, K. (2008). Artificial neural networks for the modelling and fault diagnosis of technical processes. Springer.

Sánchez, L. K. M., Hernández, E. H. O., Fernández, L. S. Q., \& Párraga, W. E. R. (2018). Determination of Physical and Mechanical Properties of Quarries Dos Bocas Mouths and Mine Copeto for High Resistance Concretes. International Research Journal of Engineering, IT \& Scientific Research, 4(2), 33-40.

Silva Neto, A. J. (2012). An inverse analysis of the radiative transfer in a two-layer heterogeneous medium. Inverse Problems in Science and Engineering, 20(7), 917-939.

Silva Neto, A. J., \& Moura Neto, F. D. (2005). Inverse Problems-Fundamental Concepts and Applications. EdUERJ, Rio de Janeiro.(In Portuguese).

Silva-Neto, A. J., \& Becceneri, J. C. (2009). Bioinspired computational intelligence techniques-application in inverse radiative transfer problems. Notes in Applied Mathematics, SBMAC, So Carlos.

Simpen, I. N., Dewi, N. P. G. B., \& Aribudiman, I. N. (2018). Relationship between resistivity and soil strength based on geoelectric data. International Journal of Life Sciences, 2(2), 22-29. https://doi.org/10.29332/ijls.v2n2.126

Snieder, R., \& Trampert, J. (1999). Inverse problems in geophysics. In Wavefield inversion (pp. 119-190). Springer, Vienna. 
Vt, S. E., \& Shin, Y. C. (1994). Radial basis function neural network for approximation and estimation of nonlinear stochastic dynamic systems. IEEE transactions on neural networks, 5(4), 594-603. https://doi.org/10.1109/72.298229

Wesley Hines, J. (1997). Fuzzy and Neural Approaches in Engineering MATLAB Supplement. Fuzzy and Neural Approaches in Engineering, John Wiley \& sons, New York.

\section{Biography of Authors}

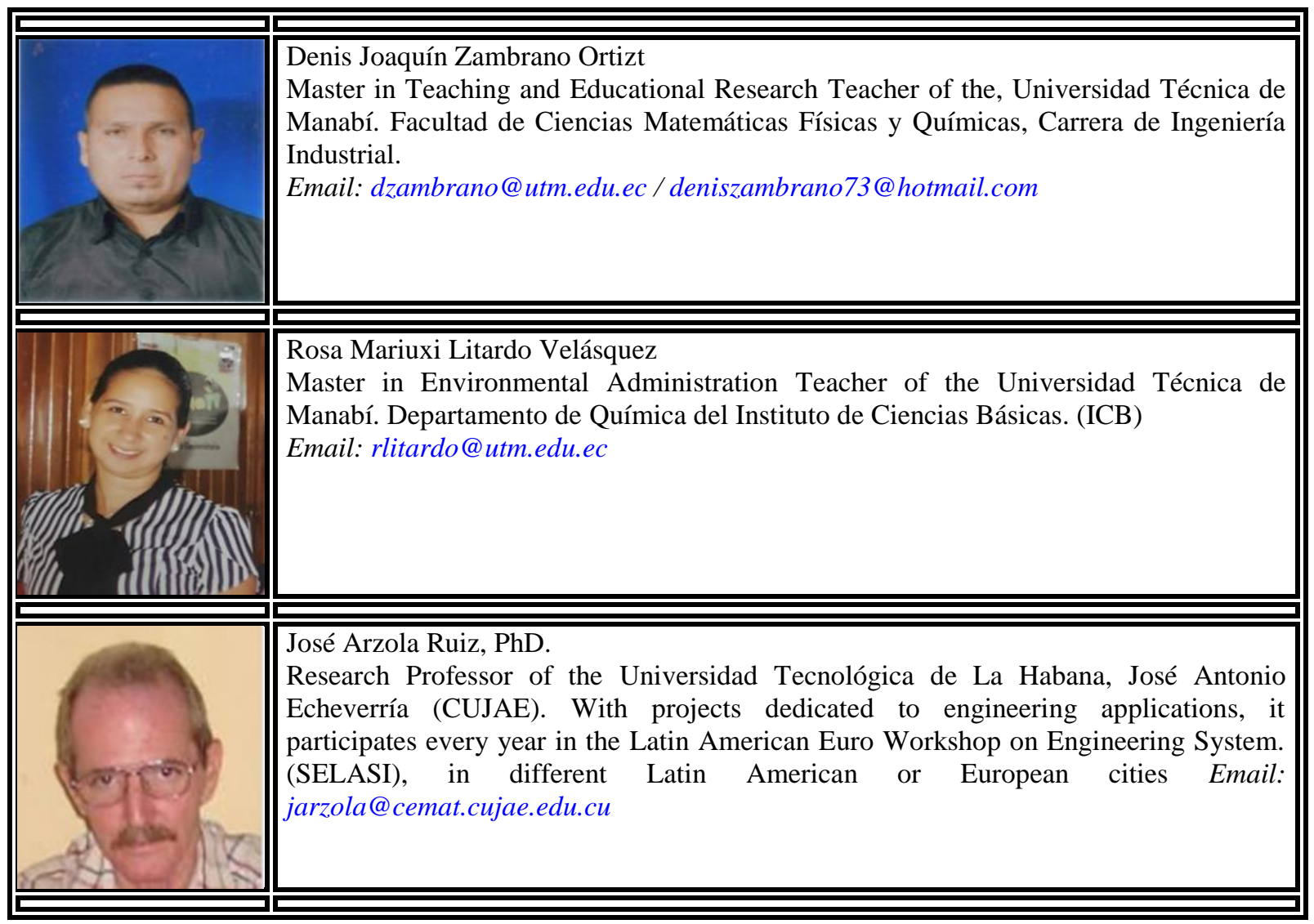

Joaquín, Z. O. D., Mariuxi, L. V. R., \& José, A. R. (2019). Comparative estimation of models with different structures for estimation of mechanical properties of light steel profiles. International Research Journal of Engineering, IT \& Scientific Research, 5(4), 16-27. https://doi.org/10.21744/irjeis.v5n4.687 